\author{
Araştırma Makalesi \\ https://doi.org/10.53803/turvehab.1013400
}

\title{
Crucianella turcica (sek. Crucianella, Rubiaceae), Türkiye'den Yeni Bir Tür
}

\author{
Ergin Hamzaoğlu \\ Matematik ve Fen Bilimleri Eğitimi Bölümü, Gazi Eğitim Fakültesi, Gazi Üniversitesi, TR-06560, Ankara, \\ Türkiye \\ Yazışmadan sorumlu yazar: Ergin Hamzaoğlu, erginhamzaoglu@gazi.edu.tr
}

$\begin{array}{lll}\text { Geliş: 22.10.2021 } & \text { Kabul: 10.11.2021 } & \text { Çevrimiçi Yayın: 31.12.2021 }\end{array}$

\begin{abstract}
Özet
Tomarza'dan (Kayseri, Türkiye) kü̧̈ük korollaları ve belirgin dört sıralı başakları ile dikkat çeken bazı ilginç Crucianella (Rubiaceae) örnekleri toplandı. Crucianella seksiyonuna ait $C$. disticha ve $C$. macrostachya türlerine benzeyen bu örnekler; düğümlerinde 4(-5) yaprak bulunması, başaklarının belirgin dört sıralı olması, bıraktelerinin eliptik-mızraksı olması, korollalarını 2,6-3,8 mm boyunda ve koralla tüplerinin boğumsuz olmasıyla farklıdır. Bu farklılıklar ilgili literatür ışığında değerlendirildi ve örneklerin bilim dünyası için yeni bir tür olduğuna karar verildi. Crucianella turcica olarak adlandırılan yeni tür, tip adresinde 1520-1600 metreler arasındaki taşlı bozkırlarda yetişir. Bu çalışmada yeni türün detaylı betimlemesi, benzerlik gösterdiği $C$. disticha ve C. macrostachya ile morfolojik karşılaştırması, türe ait bilgilendirici fotoğraflar ve bazı ekolojik tercihler verilmiştir. Ayrıca mevcut ve muhtemel yayılışı ile tespit edilen tehditler dikkate alınarak, tür için IUCN tehdit kategorisi önerilmiştir.
\end{abstract}

Anahtar kelimeler: Anadolu çaprazı, bozkır, Kayseri, Rubieae, taksonomi

\section{Crucianella turcica (sect. Crucianella, Rubiaceae), A New Species from Turkey}

\begin{abstract}
Some interesting Crucianella (Rubiaceae) specimens were collected from Tomarza, Kayseri, Turkey, which drew attention with small corollas and distinctly tetrastichous spikes. These specimens, which are like $C$. disticha and C. macrostachya, belonging to the Crucianella section, are different since they have 4(-5) leaves on their nodes, that they have distinctly tetrastichous spikes, that their bracteoles are elliptic-lanceolate, that the corollas are 2.6-3.8 mm long, and that there are corolla tubes not nodes. These differences were evaluated according to the related literature and it was decided that these specimens are a new species for the world of science. The type address of the new species, which is named Crucianella turcica, is grown in the stony, sparsely vegetated plains at an elevation of between 1520-1600 meters. In this study, the detailed description of the new species, the morphological comparison of the species with $C$. disticha and $C$. macrostachya, informative photographs for the species and some ecological preferences were given. Furthermore, by taking into consideration the threats, which were determined with the existing and probable distribution, the threat category of the International Union for Conservation of Nature (IUCN) was proposed for the species.
\end{abstract}

Keywords: Anatolian diagonal, Kayseri, Rubieae, steppe, taxonomy

\section{GİRIȘ}

Rubiaceae (Kökboyagiller), içerdiği yaklaşık 620 cins ve 13.600 türle dünyanın en fazla tür içeren dördüncü familyasıdır (Davis AP vd. 2009; Govaerts vd. 2012). Familya Türkiye'de 13 cins ve 174

Önerilen Alıntı:

Hamzaoğlu, E. (2021). Crucianella turcica (sek. Crucianella, Rubiaceae), Türkiye'den Yeni Bir Tür. Türler ve Habitatlar 2(2): 113-122. 
türle temsil edilir. 107 tür içeren Galium L. (yapışkanotu) ve 38 tür içeren Asperula L. (belumotu) en fazla tür içeren cinslerdir (Güner vd. 2012). Familyanın taksonomisinde; yaşam süresi, yaprakların dizilişi, sitipül varlığı ve şekli, çiçekdurumu, çiçekte pedisel/ovaryum oranı, kaliksin varlığ1 ve şekli, korollada tüp/lop oranı, korollada lop sayısı gibi karakterler sıklıkla kullanılır (Davis PH, 1982).

Yaklaşık 33 tür içeren Crucianella L., diğer Rubiaceae cinslerinden kolayca ayrılan monofiletik bir "Doğu-Akdeniz" cinsidir. Morfolojik ve cpDNA dizi verileri cinsin en yakın akrabalarının, kendisi gibi borazansı çiçeklere sahip olan Rubieae Baill. oymağı üyesi Galium, Phuopsis (Griseb.) Hook.f., Sherardia L. ve Asperula gibi cinsler olduğunu göstermiştir. Crucianella temel olarak, koltuğunda iki bırakteol ve 1 veya 2 çiçek taşıyan bıraktelerin oluşturduğu başaksı çiçekdurumuyla yakın cinslerden ayrılır (Manen vd. 1994; Natali vd. 1995; Ehrendorfer vd. 2005).

Flora of Turkey and the East Aegean Islands adlı eserde yer alan revizyona göre, Crucianella cinsi Türkiye'de biri çokyıllık olmak üzere toplam 10 türle temsil edilmektedir. Ayrıca revizyonda C. chlorostachys Fisch. \& C.A.Mey. türünün Türkiye'deki şüpheli varlığına dair bir açıklama da verilmiştir (Ehrendorfer 1982). Sonradan yayınlanan Flora Iranica'da, türün Orta Asya, İran, Irak ve Suriye ile birlikte Türkiye'de de yetiştiği kaydedilmiştir (Ehrendorfer vd. 2005). C. chlorostachys görünüm olarak, Türkiye, Orta Asya, Transkafkasya, İran ve Irak'ta yetişen $C$. exasperata Fisch. \& C.A.Mey. ve Filistin, Suriye ve İran'da yetişen $C$. ciliata Lam. ile benzerdir. Doğu ve güneyden Türkiye'yi çevreleyen bir yayışa sahip olan C. chlorostachys türünün Türkiye'de de bulunma ihtimali oldukça yüksektir, ancak hâlihazırda bu durumu destekleyen bir örnek toplanamamıştır.

Tomarza (Kayseri) ilçe merkezinin kuş uçuşu yaklaşık $21 \mathrm{~km}$ doğusunda, Toklar, Işıklar ve Çayinli köyleri arasında bulunan Kızıldağ, kırmızı görünümüyle çevresindeki kalker ana kayalı dağlardan hemen ayırt edilir. 2021 yılı Temmuz ayında yapılan bir botanik gezisi sırasında Kızıldağ'dan bazı ilginç Crucianella örnekleri toplandı. Örneklerin ilk dikkat çeken özelliği çiçekdurumunun belirgin dört sıralı ve çiçeklerinin bırakteler arasında gizlenmiş olmasıydı. Flora of Turkey and the East Aegean Islands, Flora Iranica, Flora of the USSR ve Flora of Iraq'ta verilen teşhis anahtarları ve notlar dikkate alınarak yapılan teşhis ve inceleme sonucunda, görünüm olarak Crucianella disticha Boiss. ve C. macrostachya Boiss.'e benzeyen bu örneklerin Crucianella cinsinin yeni bir türü olduğuna karar verildi (Ehrendorfer \& Schönbeck-Temesy 1980; Ehrendorfer 1982; Linczevsky 2000; Ehrendorfer vd. 2005). Burada tanımlanan yeni türle birlikte, Türkiye'de yetişen Crucianella tür sayısı 11'e yükselmiştir.

\section{MATERYAL VE METOT}

Yeni türün tanımında kullanılan örnekler temmuz ayı başında Kayseri ili, Tomarza ilçesi doğusunda bulunan Toklar ve Işıklar köyleri arasından toplanmıştır. Toplanan örneklerin teşhisinde Türkiye ve komşu ülke floralarından (Ehrendorfer \& Schönbeck-Temesy 1980; Ehrendorfer 1982; Linczevsky 2000; Ehrendorfer vd. 2005), GAZI, ANK, KNYA ve AYBU (Ankara Yildırım Beyazit Üniversitesi) herbaryumlarında bulunan örneklerden ve G, P ve K herbaryumlarında bulunan yüksek çözünürlüklü fotoğraflardan faydalanılmıştır (Thiers 2020). Betimlemede kullanılan terimlerin Türkçeleştirilmesinde Resimli Türkiye Florası adlı eserde yer alan "Ek 6 - Teknik Bitki Terimleri” bölümünden yararlanılmıştır (Güner vd. 2014). Örneklerin morfolojik incelenmesinde 
Leica EZ4 stero mikroskop, fotoğrafların çekiminde Nikon Coolpix S9500 fotograf makinesi ve metrik ölçümlerde $0,5 \mathrm{~mm}$ hassasiyetli cetvel kullanılmıştır.

\section{SONUÇLAR VE TARTIŞMA}

\section{Taksonomik işlem}

Crucianella turcica Hamzaoğlu, sp. nov. (seksiyon Crucianella)

Tip. Türkiye. Kayseri: Tomarza, Toklar ve Işıklar köyleri arası, Kızıldağ etekleri, 1600 m, taşlı bozkır, 4.7.2021, E.Hamzaoğlu 7877 (holotip: GAZI!; izotipler: GAZI!, ANK!).

Diagnosis. Crucianella turcica is similar to $C$. disticha, but differs mainly by its nodes with $4(-5)$ leaves (vs. with (4-)5-6(-7) leaves), spikes distinctly tetrastichous (vs. distinctly distichous), bracts elliptic-lanceolate and with $0.2-0.3 \mathrm{~mm}$ wide hyaline margins (vs. lanceolate and $0.4-0.7 \mathrm{~mm}$ wide hyaline margins), corollas 2.6-3.8 mm long (vs. (4.5-)6-8 mm long), and corolla tubes not nodes (vs. nodes).

Diyagnoz. Crucianella turcica $C$. disticha türüne benzer, fakat dügüumlerinin 4(-5) yapraklı ((4-)5-6(-7) yapraklı değil), başaklarının belirgin dört sıralı (belirgin iki sıralı değil), bıraktelerinin eliptik-mızraksı ve 0,2-0,3 mm eninde zarsı kenarlı (mızraksı ve 0,4-0,7 mm eninde zarsı kenarlı değil), korollalarının 2,6-3,8 $\mathrm{mm}$ boyunda ((4,5-)6-8 $\mathrm{mm}$ boyunda değil) ve korolla loblarının boğumsuz (boğumlu değil) olması ile ondan farklıdır.

Betimleme. Biryıllık, parlak, koyu yeşil, 10-20 cm boyunda. Gövdeler ince, çıplak, belirgin 4yüzlü, tabandan ve ortadan dallanmış. Yapraklar dügüumlerde halkamsı 4(-5) adet, çıplak, sadece ortadamar ve kenarlar seyrek pürüzlü; alttakiler çiçeklenmeden sonra solar, mızraksı veya şeritsimızraks1, yass1, sadece kenarlar alta kıvrık; orta ve üst yapraklar şeritsi, 8-18 $\times 0,4-0,8 \mathrm{~mm}$, kuvvetlice alta kıvrık. Çiçekdurumu başaksı, başaklar terminal ve lateral, (2-)4-9(-12) cm boyunda, 2-3 mm eninde, belirgin dört sıralı, yoğun, eksen seyrek pürüzlü, başak sapları kısa veya uzun, yükselici veya yaygın. Bırakteler bir çiçek taşır, kiremitvari, 5-6 × 0,9-1,4 mm, eliptikmızraksı, omurgalı, kenarlar yassı, 0,2-0,3 mm eninde dar kıkırdaksı, yeşil kısım kıkırdaksı kısımdan daha geniş, kenarlar aşağıda düz, yukarıda kirpikli, yüzey çıplak veya seyrek kısa havlı, uç sivri ve 0,2-0,3 mm kısa kıkırdaksı kılçıklı; bırakteoller 2, bırakte boyu kadar, benzer yapıda fakat daha dar. Korolla 5-parçalı, sarımsı-krem, 2,6-3,8 mm boyunda, biraktelerden biraz uzun veya biraz kısa, tüp seyrek pürüzlü, boğumsuz, loblar memecikli. Meyve yüzeyi ince tanecikli.

Etimoloji. Yeni tür, keşfedildiği ülkeden (Türkiye) esinlenerek adlandırılmıştır.

Türkçe isim. Türün Türkçe ismi belirlenirken, yetiştiği habitattan (bozkır) esinlenilmiştir.

Habitat ve ekoloji. Crucianella turcica Kızıldağ'da (Kayseri, Tomorza) 1520-1600 metreler arasındaki az eğimli taşı bozkırları tercih eder (Şekil 1). Türün çiçeklenme dönemi haziran başından temmuz ortasına kadardır. Fumana procumbens (Dunal) Gren. \& Godr., Inula montbretiana DC., Convolvulus boissieri Steud. subsp. compactus (Boiss.) Stace, Koeleria pyramidata (Lam.) P.Beauv., Centaurea virgata Lam., Thymus sipyleus Boiss., Bromus tomentellus Boiss., Paronychia kurdica Boiss., Acantholimon caryophyllaceum Boiss. subsp. caryophyllaceum, Ziziphora tenuior L., Ferulago pauciradiata Boiss. \& Heldr., Erysimum crassipes Fisch. \& C.A.Mey., Odontarrhena muralis (Waldst. \& Kit.) Endl., Gelasia cinerea (Boiss.) Zaika, Sukhor. \& N.Kilian, Centaurea cariensiformis Hub.-Mor., Taeniatherum caput-medusae (L.) Nevski subsp. crinitum (Schreb.) Melderis ve Festuca cappadocica (Hack.) Markgr.-Dann. türün tip adresinde sıklıkla gözlenen diğer türlerdir. 


\section{Taksonomik notlar}

Cinsin çokyıllık taksonları daha fazla atasal karakterlere sahiptir ve Doğu-Turan türlerini içeren Roseae Bornm. ve Akdeniz kıyı türlerini içeren Maritimae Bornm. seksiyonlarına dahil edilirler. Cinsin büyük çoğunluğunu oluşturan biryıllık taksonlar ise, Akdeniz, Arabistan ve Orta Asya'da yetişir ve Crucianella L. seksiyonu içinde yer alır (Manen vd. 1994; Natali vd. 1995).

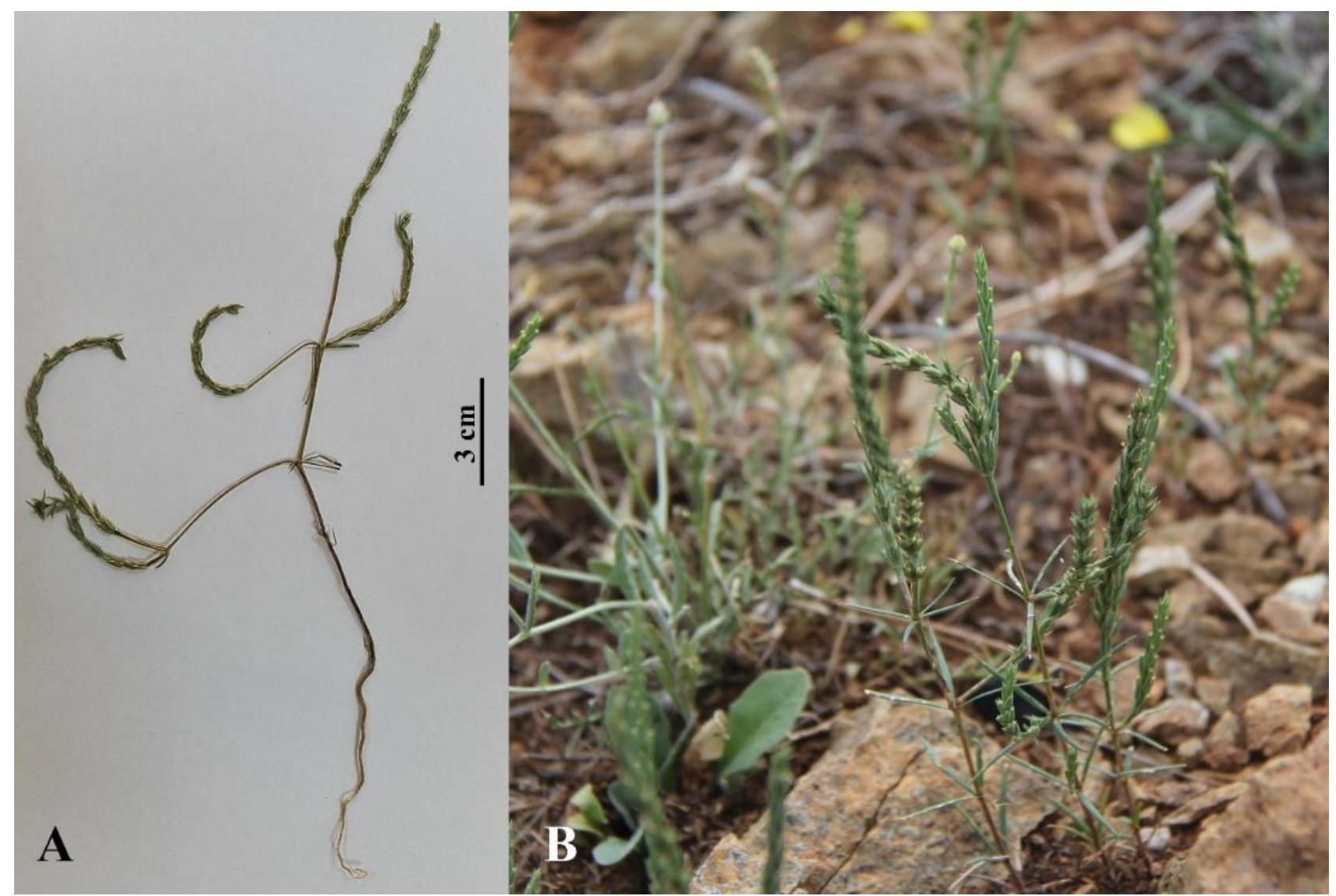

Şekil 1. Crucianella turcica. A: Holotip (E.Hamzaoğlu 7877, GAZI), B: Habit ve habitat.

Crucianella turcica benzerlik gösterdiği ve kendisi gibi biryıllık olan $C$. disticha ve $C$. macrostachya ile birlikte Crucianella seksiyonu içinde yer alır (Ehrendorfer 1982; 2005). Flora of Turkey and the East Aegean Islands'da C. disticha ve C. macrostachya arasinda fark olarak belirtilen bitki boyu, yaprak genişliği, bırakte ve başak boyu ile başak sıklığı kısmen veya tamamen üst üste çakışan karakterlerdir ve kesin bir ayırt edicilik sağlamazlar (Şekil 2). Korolla loblarının memecikli olması (çıplak veya öbeksi tüylü değil) ve bırakte kenarının \pm alta kıvrık olması (yassı değil) karakterleri daha net bir ayırt ediciliğe sahip olmalarına karşın, incelenen örneklerde buna karar vermek oldukça zordur (Şekil 2 ve 3). Bununla birlikte; başağın belirgin iki sıralı oluşu (hafifçe dört sıralı değil), bırakte kılçığının daha kısa olması ve bırakte yüzeyinin çıplak olması ( \pm pürüzlü değil) gibi kesin olmayan farklar da belirtilmiştir. Bu çalışma kapsamında yapılan örnek incelemeleri sonucunda iki türün ayrımında kullanılabileceği düşünülen; $C$. disticha bireylerinde bırakte şeklinin mızraksı olması (yumurtamsı-mızraksı değil) ve bırakte kılçık boyunun 0,2-0,3 mm olması (0,5-1 mm değil) gibi daha kesin farklar da tespit edilmiştir (Tablo 1).

Crucianella turcica habit ve morfolojik karakterler bakımından $C$. disticha ile benzerdir. Bırakte kılçık boyu ve korolla loblarının memecikli olması, bu benzerliklerden en önemlileridir. Öte 
yandan; başak görünümü, bırakte şekli, korolla boyu ve korolla tüp yüzeyi görünümü bu iki tür arasındaki en önemli faklardır (Tablo 1, Şekil 2 ve 3). Flora of Turkey and the East Aegean Islands'da verilen ve bu çalışmada incelenen örneklerin adresleri dikkate alındığında, C. disticha türünün yayılış alanının Kayseri, Adana ve Kahramanmaraş’ta $C$. turcica türüne yaklaştığı görülmektedir (Ehrendorfer 1982). Öte yandan habitat bilgileri incelendiğinde C. disticha bireylerinin kalker ana kayayı, C. turcica bireylerinin ise kesin olmamakla birlikte kırmızı görünümü nedeniyle muhtemelen serpantin veya demir içerikli bir ana kayayı tercih ettiği söylenebilir (Şekil 1 ve 2, bkz. "İncelenen örnekler”).

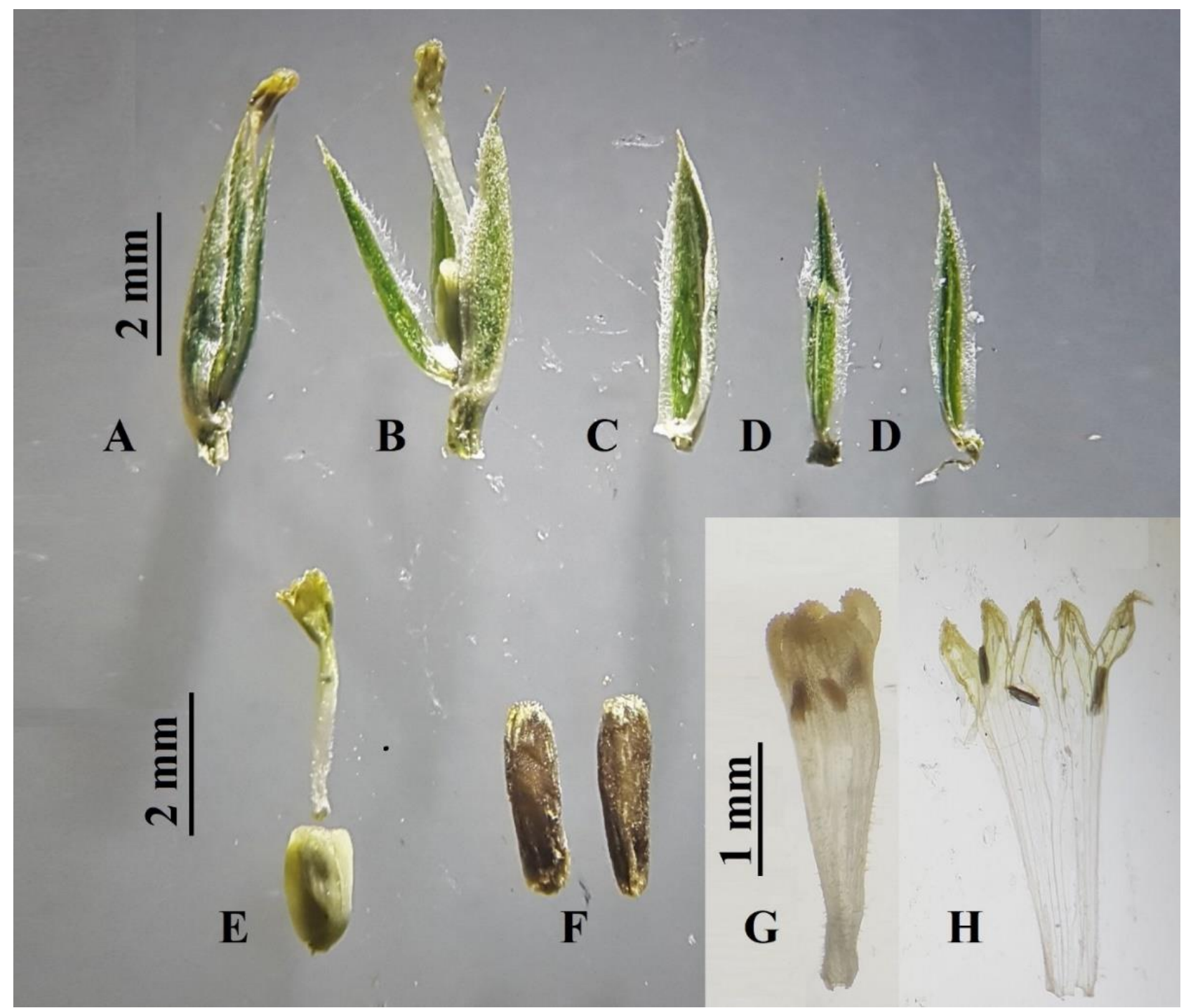

Şekil 2. Crucianella turcica. A-B: Çiçek, C: Bırakte, D: Bırakteoller, E: Korolla ve ovaryum, F: Olgun meyveler, G-H: Korolla.

$\mathrm{Bu}$ çalışma kapsamında yapılan literatür ve örnek incelemeleri sonucunda; Türkiye Crucianella cinsi türlerinden C. gilanica Trin.'nın çokyıllık olması nedeniyle, C. bithynica Boiss.'nın bırakte koltuğunda 2 çiçek taşıması nedeniyle, C. kurdistanica Malin.'nın yoğun saçaklı bırakte ve bırakteollere sahip olması nedeniyle ve $C$. sorgerae Ehrend.'nın korollasının yoğun memecikli olması nedeniyle kolay teşhis edildiği tespit edilmiştir (Ehrendorfer \& SchönbeckTemesy 1980; Ehrendorfer 1982; Linczevsky 2000; Ehrendorfer vd. 2005). Öte yandan; C. disticha 
ile C. macrostachya bireylerinin, C. exasperata Fisch. \& C.A.Mey. ile C. angustifolia L. bireylerinin ve $C$. imbricata Boiss. ile $C$. latifolia $\mathrm{L}$. bireylerinin ayırt edilmesinde sorunlar olduğu anlaşılmıştır. Gelecekte yapılacak taksonomik revizyon çalışmalarında; mevcut karakterlerin yanı sıra başak genişliği, başak orta kısmındaki düğümaralarının boyu, bırakte en/boy oranı, bırakte kenarlarındaki kıkırdaksı (zarsı) yapının genişliği, bırakteollerin ebadı, şekli, yapısı, en/boy oranı, bırakte ile bırakteoller arasındaki boy ve en oranı gibi karakterlerin de kullanılmasının faydalı olacağı değerlendirildi.

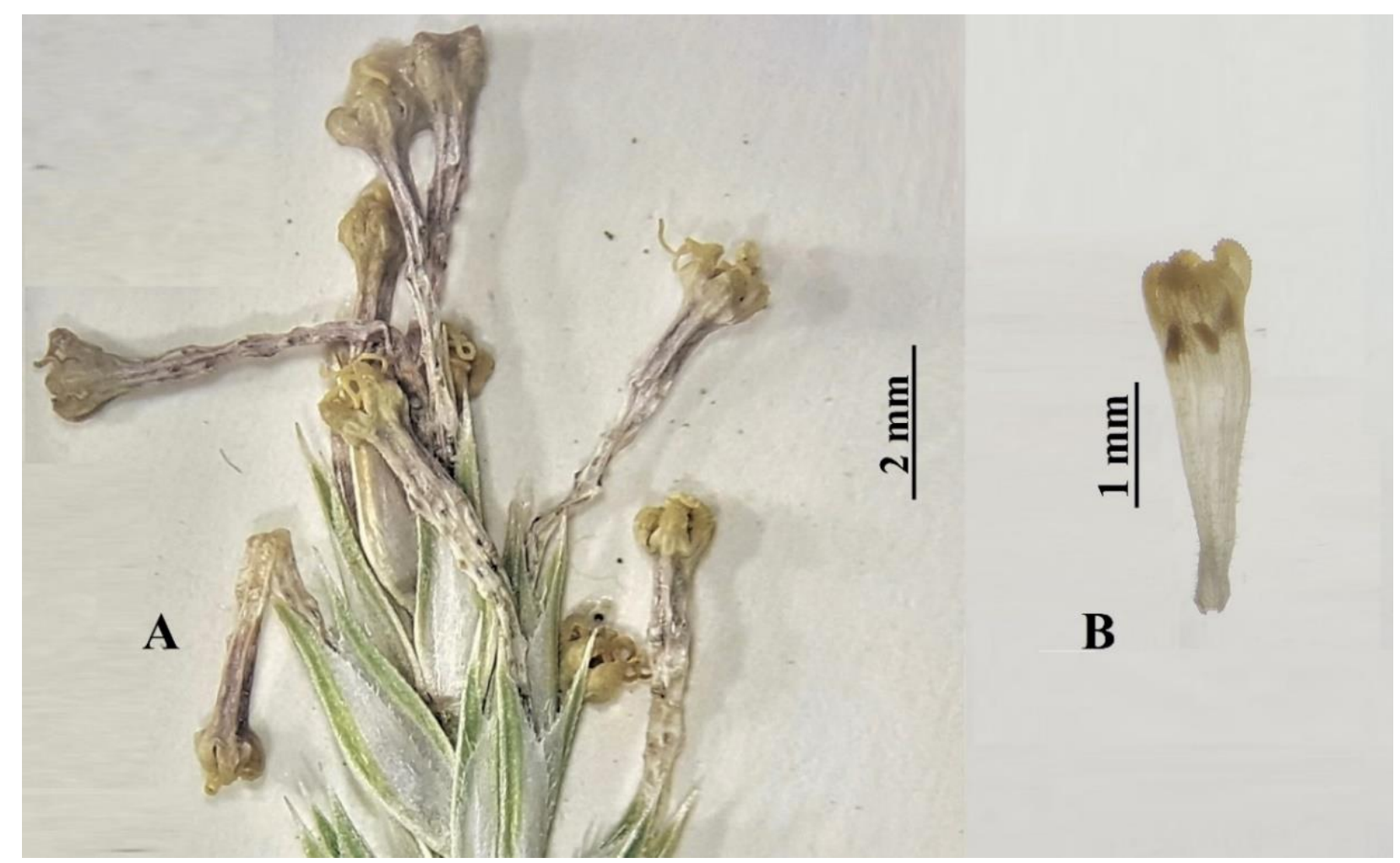

Şekil 3. A: Crucianella macrostachya (H.Duman 4119, GAZI), boğumlu korolla; B: C. turcica, boğumsuz korolla.

\section{Yayılış ve koruma durumu}

Crucianella turcica popülasyonu şimdilik sadece Kızıldağ'ın kuzey eteklerinde, Toklar ve Işıklar köyleri arasında (kuzey etekler) yaklaşık $2 \mathrm{~km}^{2}$ 'lik bir alanda gözlenmiştir. Ancak türe ait bireylerin yakın alanda benzer habitatın gözlendiği Sevügenler köyü güneydoğusunda, Güzelce köyü kuzeyinde, Melikviran köyü kuzeybatısında ve Güzelsu köyü doğusunda da yetişme ihtimali oldukça yüksektir. Türün tip adresinde $2 \mathrm{~km}^{2}$ 'lik alanda yaklaşık 1000 birey sayılmıştır. Tür az eğimli taşlı bozkırlarda yetişir ve yakın çevresinde benzer habitatın bozulmasıyla oluşturulmuş çok sayıda tarım alanı bulunmaktadır. Türün tercih ettiği habitatın tarım alanına dönüştürülme ihtimali, neslinin devamı için bir tehdit olarak değerlendirilebilir. Ayrıca türün tip adresinde ve yakınındaki benzer habitatlarda, çiftlik hayvanlarıyla yapılan yoğun otlatmanın da bir tehdit oluşturduğu düşünülebilir. Tip adres ve yakın çevresindeki benzer habitatlar dikkate alındığında, Crucianella turcica $100 \mathrm{~km}^{2}$ 'den daha küçük bir alanda yetişmektedir. Bilinen yayılış alanı genişliği ve olası tehditler birlikte ele alındığında tür için Kritik [CR: B1ab(i,iii)] tehdit kategorisinin önerilmesi uygun bulunmuştur (IUCN Standards and Petitions Committee 2019). 


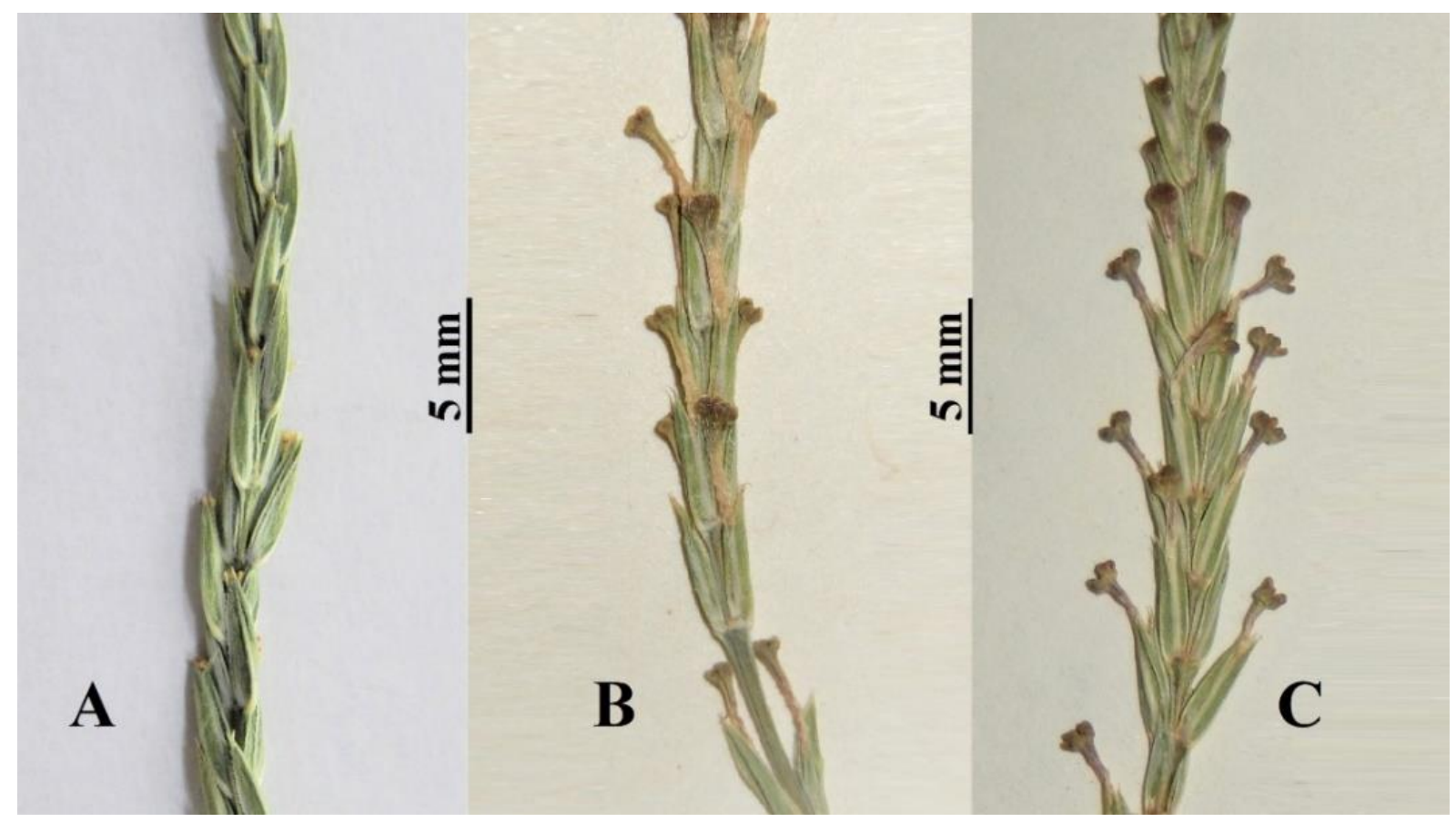

Şekil 4. Başak görünümleri. A: Crucianella turcica (E.Hamzaoğlu 7877, GAZI); B: C. disticha (H.Sümbül 3042, GAZI); C: C. macrostachya (H.Duman 4119, GAZI).

Tablo 1. Crucianella turcica ve benzer türlerin morfolojik olarak karşılaştırılması.

\begin{tabular}{|c|c|c|c|}
\hline Karakter & C. turcica & C. disticha & C. macrostachya \\
\hline $\begin{array}{l}\text { Düğümdeki yaprak } \\
\text { sayısı }\end{array}$ & $4(-5)$ & $(4-) 5-6(-7)$ & $(4-) 5-7(-8)$ \\
\hline $\begin{array}{l}\text { Üst ve orta } \\
\text { yaprakların eni }\end{array}$ & $0,4-0,8 \mathrm{~mm}$ & $0,5-1,5 \mathrm{~mm}$ & $1-3(-5) \mathrm{mm}$ \\
\hline Başak & belirgin dört siralı & belirgin iki sıralı & hafifçe dört siralı \\
\hline Birakte şekli & eliptik-mızraks1 & m1zraks1 & yumurtams1-mızraks1 \\
\hline Birakte kenarı & $\begin{array}{l}0,2-0,3 \mathrm{~mm} \text { eninde } \\
\text { kıkırdaks1 }\end{array}$ & $\begin{array}{l}\text { 0,4-0,7 mm eninde } \\
\text { kıkırdaks1 }\end{array}$ & $\begin{array}{l}0,5-0,7 \mathrm{~mm} \text { eninde } \\
\text { kıkırdaks1 }\end{array}$ \\
\hline Birakte ucu & $\begin{array}{l}\text { sivri, k1lçık 0,2-0,3 } \\
\text { mm boyunda }\end{array}$ & $\begin{array}{l}\text { sivri, kılçık 0,2-0,3 } \\
\text { mm boyunda }\end{array}$ & $\begin{array}{l}\text { sipsivri, kılçık 0,5-1 mm } \\
\text { boyunda }\end{array}$ \\
\hline $\begin{array}{l}\text { Korollanın } \\
\text { birakteye oranı }\end{array}$ & $\begin{array}{l}\text { biraktelerden biraz } \\
\text { uzun veya biraz kısa }\end{array}$ & $\begin{array}{l}\text { belirgin olarak } \\
\text { biraktelerden uzun }\end{array}$ & $\begin{array}{l}\text { belirgin olarak } \\
\text { buraktelerden uzun }\end{array}$ \\
\hline Korolla boyu & $2,6-3,8 \mathrm{~mm}$ & $(4,5-) 6-8 \mathrm{~mm}$ & $(5-) 6-8 \mathrm{~mm}$ \\
\hline Korolla tüpü yüzeyi & düz & boğumlu & boğumlu \\
\hline Korolla lobu & memecikli & memecikli & çıplak veya öbeksi tüylü \\
\hline
\end{tabular}

\section{Türkiye Crucianella cinsi türleri için güncel teşhis anahtarı}

Güncel teşhis anahtarının hazırlanmasında Flora of Turkey and the East Aegean Islands adlı eserde verilen anahtar ve betimlemelerden de yararlanılmıştır (Ehrendorfer 1982).

1. Çokyıllık gilanica

- Biryıllık 


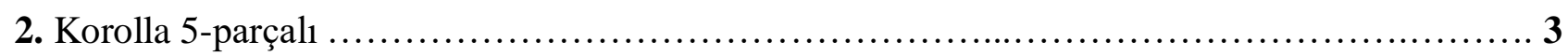

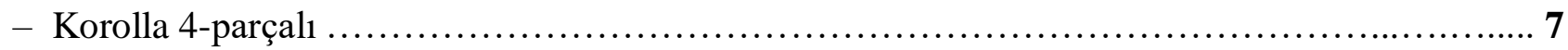

3. Yapraklar halkalarda 4 adet; her bırakte koltuğunda genellikle 2 çiçek bulunur ............. bithynica

- Bazı halkalarda yapraklar 4'ten fazla; her bırakte koltuğunda bir çiçek bulunur .................. 4

4. Bırakteler ve bırakteoller şeritsi-mızraksı, kenarlar kaba saçaklı

kurdistanica

- Bırakteler ve birakteoller yumurtamsıdan mızraksıya, kenarlar pürüzsüz veya kirpikli ........... 5

5. Başaklar 2-3 mm eninde, belirgin dört sıralı; eliptik-mızraksı, kenarlar 0,2-0,3 mm eninde kıkırdaksı; korollalar 2,6-4 mm boyunda, düz, \pm bırakteler kadar veya daha kısa turcica

- Başaklar 3,5-5 mm eninde, belirgin iki sıralı veya hafifçe dört sıralı; bırakteler mızraksı veya yumurtamsı-mızraks1, kenarlar $0,4-0,7 \mathrm{~mm}$ eninde k1kırdaks1; korollalar (4,5-)6-8 mm boyunda, boğumlu, biraktelerden uzun 6

6. Üst ve orta yapraklar 0,5-0,9 mm eninde; bırakteler mızraksı, 1-1,5 mm eninde, uç sivri ve 0,2-0,3 mm boyunda kılçıklı; korolla lobları memecikli

disticha

- Üst ve orta yapraklar 1-3(-5) mm eninde; birakteler yumurtams1-mizraksı, 1,6-2,2 mm eninde, uç sipsivri ve $0,5-1 \mathrm{~mm}$ boyunda kılçıklı; korolla lobları çılak veya öbeksi tüylü macrostachya

7. Alttaki gövde yaprakları şeritsi-mızraksı; bırakte sırtları omurgalı ......................... 8

- Alttaki gövde yaprakları yumurtams1-mızraksı; bırakte sırtları yuvarlak ......................9

8. Bıraktelerin kıkırdaksı kenarları uca doğru ani olarak daralır; yan başaklar belirgin saplı, dağınık exasperata

- Bıraktelerin kıkırdaksı kenarları uca doğru kademeli olarak daralır; yan başaklar sapsız veya kısa sapl1, dik

angustifolia

9. Korolla tüpü ve lobların uçları yoğun memecikli; bırakteler serbest sorgerae

- Korolla tüpü ve lobların uçları hafifçe memecikli veya pürüzsüz; bırakteler serbest veya kaynaşık 10

10. Düğümarası en fazla $2,5 \mathrm{~mm}$; korolla $3-5 \mathrm{~mm}$ boyunda; birakteler serbest imbricata

- Düğümarası 3-5 mm; korolla 5-7,5 mm boyunda; bırakteler tabanda \pm kaynaşık latifolia

\section{İncelenen örnekler}

Crucianella disticha. TÜRKIYYE. [İzmir] Smyrna: Smyrna (G! [G00767152] foto); [Manisa]: Pente meridionale du Tmolus occidental, au-dessus de Birghui [Birgi], 23.7.1854, B.Balansa 227 (G! [G00767144] foto; P! [P03992163] foto); [Uşak] Ouchak: Yaparlar Kevü [Yapağ1lar Köyü], Ouchak (Phrygia), 920 m, 19.7.-8.8., B.Balansa 21 (G! [G00767150] foto); Phrygia: Phrygia, 29.7.1847, B.Balansa s.n. (P! [P04579346] foto); Afyonkarahisar: Afyon-Uşak yolunun 63. km'sinde, yolun sağındaki plantasyon alanı, c. 1000 m., 11.6.1975, R.Çetik 3633 (ANK!, KNYA!); Konya: Beyşehir, Kurucaova, Asardağı, c. 1250 m, 18.6.1981, M.Serin 669 (KNYA!); Seydişehir- 
Susuz arası, Sultanpınarı mevkisi, c. 1250 m, 16.6.1980, H.Ocakverdi 972 (KNYA!); Sille, Büyükgevele tepesi, c. 1500 m, 16.6.1979, H.Dural 497 (KNYA!); Bozkır, Kuruçay üstü, Kepirlik mevkisi, c. $1500 \mathrm{~m}$, 18.6.1968, R.Çetik, T.Ekim \& E.Yurdakulol 1117 (ANK!); Akscheher [Akşehir], in campis, 1000 m, 28.6.1899, J.Bornmüller 4334 (P! [P03992212] foto, P! [P03992213] foto); Obruk, K1z1ltepe, 1250 m, 15.6.1982, H.Dural 1052 (KNYA!); Ankara: [Hacettepe Üniversitesi, Beytepe Kampüsü], Beytepe yurtları arkası, 950 m, 9.6.1997, B.Mutlu 1872 (GAZI!); Elmadağ, Irmak-Kılıçlar Köyü arası, 31.5.1972, M.Kılınç 75 (ANK!); Ankara, Cebeci, step, 17.6.1932, W.Kotte 530 (ANK); Çubuk Barajı, 7.7.1960, R.Çetik s.n. (KNYA!); Niğde: Melendiz Dağları, Okcu Köyü kuzeybatı yamaçları, c. 1700 m, 4.7.1986, B.Eyce 477 (KNYA!); Kırşehir: Hirfanlı yolu, Acıkuyu köyünün 5 km batısı, R.Çetik 7402 (KNYA!); [Antalya]: Elmalu [Elmal1], dans les collines, 15.7.1860, E.Bourgeau s.n. (P! [P03992228] foto); Karaman: Kızılyaka bucağ1, meşe koruluğu, c. 1400 m, 28.6.1984, M.Serin 2420 (KNYA!); Konya: Ermenek, Kazanc1, Koçaş mevkisi, Cedrus libani ormanı, 1500 m, 23.6.1984, H.Sümbül 3042 (GAZI!); Değirmenbaş1 Köyü civar1, Pinus nigra ormanı, c. 1450 m, 22.6.1979, M.Vural 1455 (KNYA!); Mersin: Mut'un 20 km kuzeyi, Alahan mevkisi, c. 800 m, 27.5.1974, R.Çetik 5976 (KNYA!).

Crucianella macrostachya. TÜRKIYYE. Ankara: Kızılcahamam, Soğuksu Milli Parkı, Kayabelen civarı, yol kenarı, 1100 m, 18.7.1990, Ö.Eyüboğlu 1889 (GAZI!); Delice, Büyükavşar köyü, Büyükhemit mevkisi, c. 1150 m, meşe açıklığı, C.Birden 1152 (GAZI!); Konya: Seydişehir-Susuz arası, Sultan Pınarı mevkisi, c. 1250 m, 16.6.1980, H.Ocakverdi 972 (ANK!); Kahramanmaraş: Erince Dağı, 1300-1400 m, meşe açıklığı, 26.6.1988, H.Duman 4119 (GAZI!); [Mersin]: GulekBoghas, nord de Tarsous, 21.8. (G! [G00767205] foto); ayn1 yer (ibid.), 819 (G! [G00767191] foto); Adana: Saimbeyli, Feke, c. 600 m, Davis 19650 (ANK!); Antalya: Alanya, Han Boğazı, Geyik Dağı, orman yakını, Davis 14693 (ANK!); Gündoğmuş, Geyik Dağı, Oğuz Yaylası, Geyik Oluk mevkisi, 1700-1800 m, kayalık, 2.8.1991, R.Ilarslan \& H.Dural 3048 (ANK!); Elmal1, Çığlıkara Ormanı, Avlan Beli yolu, c. 1490 m, Cedrus libani açıklı̆̆ı, 25.6.1975, R.Çetik 2160 (ANK!); aynı yer (ibid.), 2.7.1974, R.Çetik 2162 (KNYA!); Akseki, Cevizli, Gümüşdamla köyü, Halaç mevkisi, kayalık yerler, 1297 m, 12.7.2003, H.Demirelma 2619 (KNYA!). İSRAİL. Palaestina: Jerusalem, 1857, Roth 559 (G! [G00767216] foto). LÜBNAN. Libano: Libano, P.M.R.Aucher-Eloy 679 (G! [G00767232] foto; K [K000772650] foto); Liban: Amchit, 6.7.1933, P.Louis s.n. (P! [P04562563] foto); Nahr Ibrahim, 8.7.1933, P.Louis s.n. (P [P05379365] foto). SURIYE. Syria: Mai-Jul. 1846, E.Boissier s.n. (G! [G00767212] foto); Aleppo: Syrie, Aleppo, P.Louis s.n. (P! [P05379367] foto, P! [P05379374] foto).

\section{YAZAR KATKI BEYANI}

Bu makalede; çalışma fikri ve tasarımı, veri toplama, sonuçların analizi ve yorumlanması, makale taslağının yazımı aşamaları yazar tarafından yapılmıştır. Yazar sonuçları gözden geçirmiş, bask1 öncesi makalenin son halini kontrol etmiş ve onaylamıştır.

\section{KAYNAKLAR}

Davis, A.P., Govaerts, R., Bridson, D.M., Rushsam, M., Moat, J. \& Brummitt, N.A. (2009). A Global Assessment of Distribution, Diversity, Endemism, and Taxonomic Effort in the Rubiaceae. Ann Mo Bot Gard 96(1): 68-78. DOI: https://doi.org/10.3417/2006205.

Davis, P.H. (1982). Flora of Turkey and the East Aegean Islands. Vol. 7. Edinburgh University Press, Edinburgh, pp. 722-861. 
Ehrendorfer, F. \& Schönbeck-Temesy, E. (1980). [Crucianella L.] In: Towsend, C.C. \& Guest, E.R. (Eds.) Flora of Iraq. Vol. 4 (part 1). Royal Botanic Gardens, Kew, pp. 574-580.

Ehrendorfer, F. (1982). [Crucianella L.] In: Davis, P.H. (Ed.). Flora of Turkey and the East Aegean Islands. Vol. 7. Edinburgh University Press, Edinburgh, pp. 725-733.

Ehrendorfer, F., Schönbeck-Temesy, E., Puff, C. \& Reshinger, W. (2005). [Crucianella L.] In: Flora Iranica. Vol. 176. Verlag des Naturhistorischen Museum, Wien, pp. 161-258.

Govaerts, R., Ruhsam, M., Andersson, L., Robbrecht, E., Bridson, D.M., Davis, A.P., Schanzer, I.A. \& Sonké, B. (2012). World Checklist of Rubiaceae. http://apps.kew.org/wcsp/. [10.10.2021].

Güner, A., Aslan, S., Ekim, T., Vural, M. \& Babaç, M.T. (Eds.). (2012). Türkiye Bitkileri Listesi (Damarlı Bitkiler). Nezahat Gökyiğit Botanik Bahçesi ve Flora Araştırmaları Derneği Yayını. İstanbul, pp. 816-833.

Güner, A., Karabacak, E., Çıngay, B., Güneş, F., Eker, İ., Öztekin, M., Keskin, M. \& Körüklü, T. (2014). [Ek 6 - Teknik Bitki Terimleri] In: Güner, A. (Ed.). Resimli Türkiye Florası. Cilt 1. Nezahat Gökyiğit Botanik Bahçesi, İstanbul, pp. 445-527.

IUCN Standards and Petitions Committee (2019). Guidelines for Using the IUCN Red List Categories and Criteria. Version 14. Prepared by the Standards and Petitions Committee. https://www.iucnredlist.org/resources/redlistguidelines [10.10.2021].

Linczevsky, L.A. (2000). [Crucianella L.] In: Schischkin, B.K. (Ed.). Flora of the USSR. Vol. 23. [Translated from Russian] Smithsonian Institution Libraries, Washington, pp. 169-183.

Manen, J.F., Natali, A. \& Ehrendorfer, F. (1994). Phylogeny of Rubiaceae-Rubieae inferred from the sequence of a cpDNA intergene region. Plant Syst Evol 190(3/4): 195-211.

Natali, A., Manen, J.F. \& Ehrendorfer, F. (1995). Phylogeny of the Rubiaceae-Rubioideae, in Particular the Tribe Rubieae: Evidence from a Non-coding Chloroplast DNA Sequence. Ann Mo Bot Gard 82(3): 428-439. DOI: https://doi.org/10.2307/2399892.

Thiers, B. (2020). Index Herbariorum: A Global Directory of Public Herbaria and Associated Staff. New York Botanical Garden's Virtual Herbarium. http://sweetgum.nybg.org/ science/ih/. [12.10.2021]. 